\title{
Differential moderating effect of locus of control on effect of driving experience in young male and female drivers
}

\author{
Carol Holland, Jennifer Geraghty and Kruti Shah, \\ Psychology, \\ School of Life \& Health Sciences, \\ Aston University,
}

Birmingham, B4 7ET,

UK

Keywords: Locus of control; driver styles; MDSI; young drivers; gender differences;

driver experience.

This is the refereed and amended version of the paper as accepted for the journal Personality and Individual Differences, Holland, Geraghty and Shah (2010) Vol 48, p821-826. The publishers PDF can be retrieved from http://dx.doi.org/10.1016/j.paid.2010.02.003 subject to your access. Copyright of this version rests with the author Dr. C. Holland. 


\begin{abstract}
Investigations of relationships between the specific personality variable, locus of control (LOC, Rotter, 1966) and driver behaviour or accidents have returned contrasting results. Review suggests dependence on gender or experience characteristics of participants, suggesting these factors interact with LOC to influence driving. Relationships were investigated in terms of influence on the eight driving styles of the Multidimensional Driving Style Inventory (MDSI, Taubman-Ben-Ari, Mikulincer \& Gillarth, 2004) in young drivers (18-29 years). Gender and LOC differences in driving styles previously related to accidents were proposed. It was also proposed that driving experience influences driving style, and LOC influences effect of driving experience. Gender differences were found for dissociative, anxious, patient, risky, angry and high velocity styles. Women had more external LOC than men, and driver stress styles increased with more external LOC, but reduced with increased driving experience, but so did patient style. High velocity style increased with experience. Controlling for LOC revealed important gender differences in effect of experience: positive effects for men (reducing angry and high velocity, increasing carefulness) and negative effects for women (increasing angry and higher velocity, reducing carefulness). Findings suggest negative influence of high internal LOC on young men in terms of its interaction with experience.
\end{abstract}




\section{Introduction}

Those aged 17 to 25 years represent $7 \%$ of license holders in the UK but are involved in $13 \%$ of injury accidents (Royal Society for the Prevention of Accidents, 2007). In addition, road accidents and traffic violations are approximately $60 \%$ higher in young and middle aged male drivers compared to their female counterparts (Kweon \& Kockelman, 2003). Gender differences in driving behaviour and accident rates have been reliably replicated (Lonczak, Neighbors \& Donovan, 2007). These findings underline the importance of research into driving behaviour and skills amongst younger drivers, particularly since $90 \%$ of road traffic accidents are said to be directly attributable to human factors (Lewin, 1982).

Personality and behaviour have been well-cited as causes of such accident differences, with male drivers demonstrating more aggressive driving behaviours (Shinar \& Compton, 2004), "road rage", risk taking, and violations (Westerman \& Haigney, 2000; Arnett, 1996). However, women also demonstrate some negative driver styles (Deffenbacher, Lynch, Filetti, Dahlen \& Oetting. 2003) such as driver stress, which has also been related to crashes (Taubman-Ben-Ari, Mikulincer \& Gillgarth, 2004), reminding us that young male accidents are not the only concern.

Research has also repeatedly found negative relationships between driver age and accident risk. The decrease in accident involvement is largely attributed to increasing skill with increasing experience, but the extent to which driving skill benefits from experience seems to be a more complex issue than it first appears, interacting with gender, personality and driving style. When Kweon \& Kockelman's very extensive study carefully examined crash rates per vehicle miles driven, the difference between young men and women was much less. On the one hand this suggests that young men's higher 
risk may be simply due to the fact that they drive more, but on the other hand, their higher driving experience does not make young men any less crash involved per mile driven. That is, they do not seem to benefit from greater driving experience. Experience does not seem to have as positive an effect for young men as for young women; its role as it interacts with gender is examined here.

Human factors in driving are composed of two components: driving skills and driving style. Driving style refers to the way drivers choose to drive, or habitually drive, including speed, attitudes to other road users and to rules, and general attentiveness. This is influenced by beliefs about one's own ability and what makes a good driver, as well as personality and values. Personality factors that have been investigated in terms of relationship with driving include aggression hostility (Deffenbacher, Lynch, Oetting \& Yingling, 2001), risk taking, sensation seeking and locus of control (Iversen \& Rundmo, 2002). Locus of control (LOC, Rotter, 1966) is a particularly interesting personality factor for those seeking to influence driver behaviour in terms of developing safe driving for life, since it suggests that drivers who believe outcomes are controlled by external forces (external LOC, e.g., events controlled by fate, not self), may be less likely to change behaviour in response to outcomes (Walker, Stanton \& Young, 2008) than those with internal LOC, who perceive outcomes to be dependent on their own skill, efforts or behaviour. Research on influence of LOC on driving behaviour originally suggested that externally oriented persons are more likely to be involved in car accidents, as they would take fewer precautions to prevent road accidents (Montag \& Comrey, 1987). However, increased internal LOC has also been associated with risky driving style, perhaps due to drivers' beliefs in their own ability to avoid an accident (Arthur \& Doverspike, 1992). Özkan and Lajunen (2005), using a traffic specific LOC scale (T-LOC) found that young 
drivers who attributed causes of accidents to their own behaviour (internality) had been involved in accidents and violations more frequently than those who attributed accidents to external factors (externality). However, their population was heavily biased towards male respondents (almost 2:1), and young male drivers have been shown to consistently emphasise skill factors and overestimate their own skill, particularly during their first year of driving (Spolander, 1983, cited in Lajunen \& Summala, 1995). This leads one to expect a group of young male drivers to score higher on internality, but also to examine carefully populations used in previous research. A striking feature of studies reviewed is that participants are often either all male, or biased in that direction, and are often selected for high accident involvement. For example, Trimpop and Kirkcaldy (1997) found a negative relationship between "desire for control" and risky behaviour and accidents, but only assessed young male drivers, of whom more than half were accident involved. Likewise, Montag \& Comrey (1987) found that Driving Externality (DE) was positively related to involvement in fatal accidents, using their own specifically designed scales (Montag Driving Internality Externality Scale, MDIE), but again only examining male drivers, half selected for fatal accident involvement. Accident involved respondents may respond on LOC scales to present themselves as appearing less responsible for the accident, and involvement may have led them to attribute road traffic accidents to external fault, reducing validity of findings (see Özkan \& Lajuno, 2005).

Other studies have not found any relationship between LOC and measures of driver safety: e.g. Guastello and Guastello (1986), with 17-24 year olds, using Rotter's (1966) original scale, and Iverson and Rundmo (2002) using the MDIE with a large sample of drivers well-balanced for gender, although their sample was, on average, older and more experienced as drivers than previous studies (average 23 years experience). 
Thus, studies with a balanced gender population, that have not selected specifically for high rates of serious accident involvement, and have used a general rather than specific driving LOC scale, have not found a relationship between externality and accidents or risky behaviour. As suggested above, young male drivers would be expected to have internal LOC, but only if not selected for serious accident involvement, and if tested with a general LOC scale, avoiding the possible circularity of driver specific scales.

As skill develops with increasing experience, particularly during early driving, emphasis on safety-orientation decreases (Lajunen \& Summala, 1995), and so assessing influences of gender, age, experience and LOC on driver style is particularly pertinent to research on younger drivers. A well-validated method of assessing driver style is the Multidimensional Driving Style Inventory (MDSI, Taubman-Ben-Ari, et al., 2004). This assesses eight internally consistent and coherent driving styles. Taubman-Ben-Ari et al. indicated that angry, risky and high velocity driving styles significantly predicted selfreports of car accident involvement and driving offences, and were inversely associated with the "careful" style. Specifically, once age and gender were controlled, dissociative, risky and high velocity styles made a unique contribution to accident involvement.

In summary, although previous literature has examined the role of the general personality variable LOC in predicting driving behaviour, style or accidents, the complex interactions with effects of gender and driver experience on development of driver styles during the first months and years of driving have not been examined. It is proposed that such interactions may be related to some of the gender differences reported in driving behaviour and accident outcome.

Although some previous research (Montag \& Comrey, 1987) has suggested that a LOC scale specific to driving would be a better predictor of the causes behind traffic 
accidents, other research (Lajunen \& Summala, 1995) found that a general LOC scale may be more closely related to driver behaviour. For this reason, a general scale (Rotter, 1966) was judged appropriate here.

In summary, hypotheses of this study are:

1) There will be significant differences between genders for driving styles previously shown to be related to accidents.

2) There will be significant differences between participants scoring as Internal and External on the LOC scale for driving styles previously shown to be related to accidents.

3) Young men and women will differ in terms of their predominant LOC.

4) (i) Driving experience (duration and amount) will influence driving style.

(ii) The interaction of LOC will influence effect of experience on driver style.

5) The influence of LOC on the effect of experience will account for gender differences in driving style.

\section{Method}

\section{$\underline{\text { Design }}$}

There were two independent variables with two levels: gender and LOC (external and internal). Dependent variables were the eight driving styles of the MDSI (Taubman-BenAri et al., 2004). Effect of driving experience was examined using covariate analyses, with correlation used to examine relationships.

\section{$\underline{\text { Participants }}$}

Participants were 122 women and 100 men aged 18 to 29 years, with a valid driving licence and a minimum of a month's driving experience, (mean age $=21.32$ years, $\mathrm{SD}=$ 2.5). Men and women differed slightly (but not significantly on a t-test) in percentage 
who had experienced an accident (37\% and 30\% respectively). Most were undergraduate students at Aston University, with volunteers enrolled on the psychology program receiving course credits for participation. Questionnaires were completed on paper or an online survey creator (Survey Monkey®).

\section{$\underline{\text { Materials }}$}

Participants were asked to give their gender, age, and driving experience on a brief demographic questionnaire. Experience was measured as number of months driving (duration) and number of hours driven per week (amount): 0-5 hours =1; 6-11 hours =2; 12-17 hours $=3 ; 17+$ hours $=4$. The MDSI (Taubman-Ben-Ari, et al., 2004) was used to measure driving style. This consists of 44 statements with a six point Likert type scale ranging from 'not at all' (1) to 'very much' (6). Statements relate to eight driving styles: (i) Dissociative (distractibility and cognitive dissociations during driving) (ii) Anxious, (driver distress, lack of confidence), (iii) Risky (risky decisions, enjoyment of risky driving) (iv) Angry (hostility towards other drivers), (v) High-velocity (drives fast, signs of time pressure whilst driving), (vi) Distress-reduction (use of relaxing activities to reduce distress), (vii) Patient (courtesy towards other drivers, planning journeys), (viii) Careful (preparedness to react, problem solving attitude).

The LOC scale (Rotter, 1966) was used to measure locus of control, consisting of 29 pairs of statements (6 filler, 23 scored).

\section{Procedure}

Participants were given a participant number to use instead of their name to assure anonymity, and notified of their right to withdraw. They were asked to complete answers with what they believed to be true despite what they may have liked to be true, and informed that there were no right or wrong answers. The LOC questionnaire was scored 
using a median split (0-11 represented internal LOC, "internals"; 12-23 represented external LOC, “externals”). The MDSI was scored by calculating the average score of each of the eight driving styles.

\section{Results}

\section{Gender and LOC differences in driving styles}

Means and standard deviations for each of the driving styles and demographic variables are given in Table 1

\section{Table 1 about here}

Two way ANOVAs were conducted to examine gender and LOC differences in driving styles, with partial $\eta^{2}$ used to give effect size, $(0.01=$ small effect, $>0.15=$ large effect, Murphy \& Myors, 2004). Women scored significantly higher on dissociative, anxious, and patient driving styles, and men scored higher on risky, angry and high velocity driving style, all $p<0.01$, see Table 2 . In order to determine whether gender effects were related to differences in driving experience, analyses of covariance were computed with each measure of driving experience as covariate. Results demonstrated an effect of amount of driving (hours) on dissociative, anxious, angry and high velocity driving responses (all at least $p<0.05$ ), in all cases slightly reducing the gender effect, which remained significant, suggesting that although robust, part of the gender effect was due to differences in amount of experience. When duration of driving (months) was entered as covariate, only the effect on anxious driving style was significant $(p<0.001)$, slightly reducing the gender effect, which remained significant at $p<0.001$.

\section{Table 2 about here}


Externals scored significantly higher than internals on dissociative, high velocity and distress reduction driving styles, (at least $p<0.05)$. There were no significant Gender $\mathrm{x}$ LOC interactions for any driving style.

Investigation into the association between gender and locus of control

Women had a higher (more external) total LOC score than men, $F(1,219)=5.69, p<0.05$, partial $\eta^{2}=0.03$. Confirming this, men were more likely to be classified as internals LOC and women as externals than would be expected, $\mathrm{X}^{2}=6.38, d f=1, p<0.05$.

\section{Correlations between driving styles and driving experience}

Correlations are given in Table 3. A significant negative relationship was revealed between duration of driving experience and dissociative and anxious driving styles $(p<$ 0.05 and $p<0.01$ respectively). Thus the more experience a driver has, the less dissociative and anxious their driving style. This was replicated in the relationship with amount of driving (both $p<0.01$ ). This measure also correlated negatively with patient driving: the more a participant drives, the less patient their driving style $(p<0.05)$. In contrast, this measure correlated positively with high velocity driving: the more a person drove, the higher they scored on this style $(p<0.05)$.

\section{Table 3 about here}

As there were clear gender effects, and also given gender differences in published accident statistics, correlation analyses were repeated for men and women separately (Table 3). The negative relationship between duration of driving and dissociative driving style was replicated for men only, but that for anxious style replicated for both genders. Amount of driving correlated positively for high velocity style for men only. Significant negative correlations for amount of driving with dissociative and anxious styles were 
only replicated for women (both $p<0.01$ ). For women, angry driving style increased the longer they had been driving $(p<0.05)$.

\section{Correlations between driving styles and LOC}

There were significant positive correlations between LOC and dissociative, anxious and distress reduction driving styles (Table 3). The higher the LOC (more external), the more likely each of these driving styles was adopted. This was replicated for dissociative driving style for women when analyses were conducted separately for each gender, but not for men.

In order to examine influence of LOC on effect of experience, partial correlations were conducted between experience measures and driving styles, controlling for LOC. Clear effects were shown specifically for angry and high velocity driving styles, such that both these now showed a significant positive relationship with amountof driving $[r(216)$ $=0.15$ and 0.152 , respectively, both $p<0.05]$.

Correlations for men revealed that once LOC was controlled, the positive effect of duration of driving experience on reducing angry and high velocity driving style was increased $[r(96)=0.177, p=.08 ; r(96)=0.184, p=.07$ respectively], although this was still non-significant. However, more dramatically, the almost negligible positive relationship between duration and carefulness increased to become significant, $r(96)=0.22, p<0.05$. For women, relationships changed in a more negative direction such that once LOC was controlled, greater experience increased angry and high velocity driving to a greater extent $(r(117)=0.23, p=0.01 ; r(117)=0.17, p=0.06$ respectively $)$ and reduced careful driving $(r(117)=-.13)$, although the latter relationship was not significant.

\section{Discussion}


The purpose of this research was to examine effects of relationships between gender, locus of control and experience on driving style. Given differences in accident statistics between young men and women, and relationships between driving style and accidents demonstrated in the literature, gender differences in driving styles were hypothesised. This was supported in that men scored higher on risky, angry and high velocity driving styles, supporting Taubman-Ben-Ari et al.'s, (2004) demonstration that angry, risky, high velocity and dissociative styles were associated with self report of accidents. Women scored higher on dissociative, anxious and patient driving styles. Although accident data suggests higher accident involvement for men, these gender differences suggest that different styles may be predominant in accident causation for different genders, with risky and high velocity styles being predominant for men, but accident related dissociative and anxious styles (Westerman \& Haigney, 2000) being predominant for women. In accordance with the literature (Simon \& Corbet 1996; Taubman-Ben-Ari et al., 2004) women exhibited more driving stress than men (dissociative and anxious styles).

The hypothesis that LOC orientation would be associated with driving styles was also supported: those with external LOC scored higher on dissociative, high velocity and distress reduction styles. This supports suggestions that those with an external LOC may, in some circumstances, experience greater accident risk, given associations between both dissociative and high velocity styles and accident occurrence (Taubman-Ben-Ari et al., 2004). Results support those of earlier studies which have also not demonstrated any association between locus of control and risky driving (Arthur \& Doverspike, 1992; Iversen \& Rundmo, 2002). 
The hypothesis that young men and women would differ in LOC was supported in that women were more external than men. Our review demonstrated that externality seemed to be associated with accidents only where there was a preponderance of young men who had been involved in serious accidents in the sample, who may be expected to answer in an external manner. That is, although externality is associated with dissociative and anxious driving, which have been, in turn associated with errors and accidents, the finding that young women were more likely to be classified as having external LOC, and LOC was not associated with more male driver relevant styles such as risky driving, goes some way towards explaining variation in previous findings.

However, simple differences in populations are not the only factor underlying the varying effects of LOC found in the literature. The role of experience is demonstrated as an important factor. Driver stress (anxious and dissociative style) was ameliorated by experience for both genders, but duration of driving was the salient influence for men and amount driven for women. These findings have implications for planning driver training schedules differently for young men and women. In addition, for men, greater weekly time spent driving was related to reduced patient driving and increased high velocity style (not for women), but for women, longer experience as a driver, while reducing anxiety, also increased angry driving style.

The hypothesis that LOC influenced effect of experience on driver style was also proposed, given suggestions (Montag \& Comrey, 1987) that external LOC would reduce effect of feedback from experience, since drivers may assume events were not due to their own skill or behaviour, and conversely, drivers with internal LOC may take risks because of greater belief in their own control over outcomes (Arthur \& Doverspike, 1992; Özkan \& Lajunen, 2005). Once the moderating effect of LOC was controlled, angry and 
high velocity styles increased with amount of driving. Significantly, the moderating effect of LOC on experience effects differed for each gender, possibly accounting for gender differences in driver style. When influence of LOC was controlled, the positive effect of duration of driving experience on reducing angry and high velocity driving style increased for men. More dramatically, the almost negligible positive relationship between duration and carefulness increased to become significant. This strongly suggests that the higher internal LOC of the young men sampled was having a negative effect on the positive influence of experience. In contrast, the increased negative effect of experience for women once LOC was controlled suggests that their higher externality was having a positive influence on effect of experience.

Notably, although men scored higher on the angry driving scale, even controlling for experience, this negative style increased for women with increasing experience. It would be likely that all drivers would experience more inconsiderate driving, progress being impeded and impatient driving with increased amount and duration of driving, which may result in increased angry styles. A basis of this is the idea that need for control (internal LOC) is a psychological source of angry driving style (Taubman-Ben-Ari et al., 2004), the driver being unable to control incidents such as impeded progress. Driving anger has been related to aggressive and risky behaviour (Deffenbacher et al., 2003) and increased accidents (Underwood, Chapman, Wright \& Crundall, 1999). Findings highlight the need to develop effective counter-measures to reduce anger experienced whilst driving, and focussing on beliefs related to high internal LOC, or perceived control in young drivers may be a useful route for intervention.

A further useful indicator of the influence of LOC was that the more internal LOC, the less anxiety reported. Lazarus (1966) proposed that lower perceived control in a 
threatening situation results in higher stress. Drivers who believe in events being outside of their control seemed to experience more anxiety whilst driving. This indicates pathways for intervention to allay anxious driving, given that driver anxiety can increase risk, but also often results in avoidance and limitation of independent mobility.

A rather worrying result is that the more hours driven per week by male drivers, the more likely it is that a high velocity driving style is adopted. This was, however, offset by a reducing factor of duration of experience on the same style for young men. The finding that this latter effect was enhanced once the negative effect of internal LOC was controlled for statistically gives clear implications for selection and training of professional drivers.

\section{Conclusion:}

This research provides further evidence that female drivers exhibit more driving stress than male drivers, and male drivers exhibit more risky styles than female drivers. Both extremes can be linked to accidents and errors and this evidence suggests that accidents for young men and women may have different human factors causalities. Although influence of LOC seems to have varied in the literature, factors such as population sampling seem to account for this and this study has shown that the high internality of young men in general may be having negative influences on the development of safer driving styles with increasing experience, but that the generally higher externality of young women may be having a suppressing effect on the negative influence of greater experience on developing angry styles. Experience was shown to have a generally positive influence on anxious and dissociative driving styles (the "stress" styles), but amount of driving was the more important experience variable for women, who show more of this problem than men. 
The considerable human and economic cost of traffic accidents highlights the need for research into driving behaviour. This research has underlined the role of a specific personality factor, locus of control, in safe and unsafe driving styles, and specifically, highlighted important interactions with gender and experience that go some way towards explaining the puzzle of why young men continue to have higher risk than young women as drivers despite their greater experience. Findings may provide guidance on counter-measures that could be developed in order to reduce accident risk, such as alerting driving examiners to behavioural markers that would predict accident related styles, informing further training for new drivers once licensed, and informing driver style management for individuals. 


\section{References}

Arnett, J.J. (1996). Sensation seeking, aggressiveness and adolescent reckless behaviour. Personality and Individual Differences, 20, (6), 693-702.

Arthur, W. Jr. \& Doverspike, D. (1992). Locus of control and auditory selective attention as predictors of driving accident involvement: A comparative longitudinal investigation. Journal of Safety Research, 23, 73-80.

Deffenbacher, J.L., Lynch, R.S., Oetting, E.R. \& Yingling, D.A. (2001). Driving anger: correlates and a test of state-trait theory. Personality and Individual Differences, 31, $1321-1331$.

Deffenbacher, J.L., Lynch, R.S., Filetti, L.B., Dahlen, E R. \& Oetting, E.R. (2003). Anger, aggression, risky behaviour and crash-related outcomes in three groups of drivers. Behaviour research and therapy, 41, 333-349.

Guastello, S.J., \& Guastello, D.D. (1986).The relation between locus of construct and involvement in traffic accidents. The Journal of Psychology, 120, (3), 293-297.

Iversen, H. \& Rundmo, T. (2002). Personality, risky driving and accident involvement among Norwegian drivers. Personality and Individual Differences, 33, 1251-1263.

Kweon, Y.J. \& Kockelman, K.M. (2003). Overall injury risk to different drivers: combining exposure frequency, and severity models. Accident Analysis and Prevention, 35, 441450.

Lajunen, T. \& Summala, H. (1995). Driving experience, personality, and skill and safety-motive dimensions in driver's self-assessments. Personality and Individual Differences, 19, (3), 307-318.

Lazarus, R.S. (1966). Psychological stress and the coping process. New York: McGraw Hill, Lewin, I. (1982). Driver training: A perceptual motor skill approach. Ergonomics, 25, 917-924. 
Lonczak, H.S., Neighbors, C. \& Donovan, D.M. (2007). Predicting risky and angry driving as a function of gender. Accident and Analysis, 39, 536-545.

Montag, I. \& Comrey, A.L. (1987). Internality and externality as correlates of involvement in fatal driving accidents. Journal of Applied Psychology, 72, 339-343.

Murphy, K.R. and Myors, B. (2004) Statistical power analysis: A Simple and General Model for Traditional and Modern Hypothesis Tests. $2^{\text {nd }}$ Edition, Mahwah, N.J. Lawrence Erlbaum Associates.

Özkan, T. \& Lajunen, T. (2005). Multidimensional Traffic Locus of Control Scale (T-LOC): factor structure and relationship to risky driving. Personality and Individual Differences, $38,533-545$.

Rotter, J.B. (1966). Generalised expectancies for internal versus external locus of control of reinforcement. Psychological Monographs, 80, (609), 1-28.

Royal Society for the Prevention of Accidents (2007). Novice drivers-facing the risk-preparing for the future. National Road Safety Congress: Stratford upon Avon.

Shinar, D. \& Compton, R. (2004). Aggressive driving: An observational study of driver, vehicle, and situational variables. Accident Analysis and Prevention 36, 429-437.

Simon, F., Corbet, C. (1996). Road traffic offending, stress, age, and accident history among male and female drivers. Ergonomics 39, 757- 780.

Taubman-Ben-Ari, O., Mikuliner, M. \& Gillath, O. (2004). The multidimensional driving inventory- scale construct and validity. Accident Analysis and Prevention 36, 323-332.

Trimpop, R. \& Kirkcaldy, B. (1997). Personality predictors of driving accidents. Personality and Individual Differences, 23, 147- 152.

Underwood, G., Chapman, P., Wright, S. \& Crundall, D. (1999). Anger while driving. Transport research part $F, 2,55-68$. 
Walker, G.H., Stanton, N.A. and Young, M.S. (2008) Feedback and driver situation awareness (SA): A comparison of SA measures and contexts. Transportation Research Part F, 11. 282-299.

Westerman, S.J. \& Haigney, D. (2000). Individual differences in driver stress, error and violation. Personality and Individual Differences, 29, 981-998. 


\section{Tables}

Table 1. Means and S.D. of multidimensional driving style inventory (MDSI) factors and demographic variables according to gender and locus of control (LOC)

Table 2. ANOVA results for multidimensional driving style inventory (MDSI) factors according to gender, locus of control (LOC) and interaction.

Table 3. Correlations (Spearmans rho) between driving style, locus of control (LOC), hours driven /week and driving experience (years). 
Table 1

\begin{tabular}{|c|c|c|c|c|c|}
\hline \multicolumn{2}{|c|}{ MDSI Factor } & $\begin{array}{c}\text { Males } \\
(n=100)\end{array}$ & $\begin{array}{r}\text { Females } \\
(n=122)\end{array}$ & $\begin{array}{c}\text { Internal LOC } \\
(\mathbf{n}=102)\end{array}$ & $\begin{array}{c}\text { External LOC } \\
(n=119)\end{array}$ \\
\hline Dissociative & $\begin{array}{l}\text { Mean } \\
\text { S.D. }\end{array}$ & $\begin{array}{l}1.79 \\
0.53\end{array}$ & $\begin{array}{c}2.14 \\
0.59\end{array}$ & $\begin{array}{l}1.81 \\
0.52\end{array}$ & $\begin{array}{l}2.12 \\
0.67\end{array}$ \\
\hline Anxious & $\begin{array}{l}\text { Mean } \\
\text { S.D. }\end{array}$ & $\begin{array}{c}2.03 \\
0.60\end{array}$ & $\begin{array}{l}2.65 \\
0.76\end{array}$ & $\begin{array}{l}2.26 \\
0.77\end{array}$ & $\begin{array}{l}2.47 \\
0.74\end{array}$ \\
\hline Risky & $\begin{array}{l}\text { Mean } \\
\text { S.D. }\end{array}$ & $\begin{array}{l}2.46 \\
1.01\end{array}$ & $\begin{array}{l}1.87 \\
0.81\end{array}$ & $\begin{array}{l}2.08 \\
0.91\end{array}$ & $\begin{array}{l}2.18 \\
0.98\end{array}$ \\
\hline Angry & $\begin{array}{l}\text { Mean } \\
\text { S.D. }\end{array}$ & $\begin{array}{l}2.90 \\
1.03\end{array}$ & $\begin{array}{l}2.48 \\
0.97\end{array}$ & $\begin{array}{l}2.63 \\
1.05\end{array}$ & $\begin{array}{l}2.71 \\
0.99\end{array}$ \\
\hline High-velocity & $\begin{array}{l}\text { Mean } \\
\text { S.D. }\end{array}$ & $\begin{array}{l}2.86 \\
1.03\end{array}$ & $\begin{array}{l}2.57 \\
0.81\end{array}$ & $\begin{array}{l}2.59 \\
0.91\end{array}$ & $\begin{array}{l}2.79 \\
0.94\end{array}$ \\
\hline $\begin{array}{l}\text { Distress- } \\
\text { reduction }\end{array}$ & $\begin{array}{l}\text { Mean } \\
\text { S.D. }\end{array}$ & $\begin{array}{l}2.36 \\
0.82\end{array}$ & $\begin{array}{l}2.37 \\
0.73\end{array}$ & $\begin{array}{l}2.25 \\
0.82\end{array}$ & $\begin{array}{l}2.46 \\
0.72\end{array}$ \\
\hline Patient & $\begin{array}{l}\text { Mean } \\
\text { S.D. }\end{array}$ & $\begin{array}{l}4.28 \\
0.81\end{array}$ & $\begin{array}{l}4.59 \\
0.68\end{array}$ & $\begin{array}{l}4.49 \\
0.79\end{array}$ & $\begin{array}{l}4.42 \\
0.73\end{array}$ \\
\hline Careful & $\begin{array}{l}\text { Mean } \\
\text { S.D. }\end{array}$ & $\begin{array}{l}4.62 \\
0.67\end{array}$ & $\begin{array}{l}4.73 \\
0.63\end{array}$ & $\begin{array}{l}4.73 \\
0.62\end{array}$ & $\begin{array}{l}4.64 \\
0.67\end{array}$ \\
\hline Age & $\begin{array}{l}\text { Mean } \\
\text { S.D. }\end{array}$ & $\begin{array}{c}21.86 \\
2.52\end{array}$ & $\begin{array}{c}20.88 \\
2.42\end{array}$ & $\begin{array}{c}21.45 \\
2.47\end{array}$ & $\begin{array}{c}21.21 \\
2.54\end{array}$ \\
\hline $\begin{array}{l}\text { Duration of } \\
\text { driver } \\
\text { experience } \\
\text { (Months) }\end{array}$ & $\begin{array}{l}\text { Mean } \\
\text { S.D. }\end{array}$ & $\begin{array}{l}48.72 \\
30.14\end{array}$ & $\begin{array}{l}35.54 \\
29.63\end{array}$ & $\begin{array}{l}42.83 \\
26.95\end{array}$ & $\begin{array}{l}40.25 \\
33.31\end{array}$ \\
\hline $\begin{array}{l}\text { Amount of } \\
\text { driver } \\
\text { experience }^{\text {a }} \\
\text { (Hrs/week) } \\
\text { Locus of } \\
\text { Control }\end{array}$ & $\begin{array}{l}\text { Mean } \\
\text { S.D. }\end{array}$ & $\begin{array}{c}11.11 \\
4.03\end{array}$ & $\begin{array}{c}12.19 \\
3.97\end{array}$ & $\begin{array}{l}1.69 \\
0.80\end{array}$ & $\begin{array}{l}14.80 \\
2.32\end{array}$ \\
\hline $\begin{array}{l}\text { Total number } \\
\text { of accidents }\end{array}$ & & 43 & 57 & 51 & 49 \\
\hline
\end{tabular}

${ }^{\mathrm{a}} 0-5$ hours $=1 ; 6-11$ hours $=2 ; 12-17$ hours $=3 ; 17+$ hours $=4$. 
Table 2.

\begin{tabular}{|c|c|c|}
\hline MDSI Factor & F ratio & Partial $n^{2}$ \\
\hline \multicolumn{3}{|l|}{ Dissociative } \\
\hline Gender & $14.12 * *$ & .061 \\
\hline LOC & $9.84 * *$ & .043 \\
\hline Gender * LOC & 1.09 & .005 \\
\hline \multicolumn{3}{|l|}{ Anxious } \\
\hline Gender & $39.44 * *$ & .154 \\
\hline LOC & 1.47 & .007 \\
\hline Gender * LOC & 0.33 & .002 \\
\hline \multicolumn{3}{|l|}{ Risky } \\
\hline Gender & $23.79 * *$ & .099 \\
\hline LOC & 2.97 & .014 \\
\hline Gender * LOC & 0.92 & .004 \\
\hline \multicolumn{3}{|l|}{ Angry } \\
\hline Gender & $10.70 * *$ & .047 \\
\hline LOC & 1.62 & .007 \\
\hline Gender * LOC & 0.90 & .004 \\
\hline \multicolumn{3}{|l|}{ High-Velocity } \\
\hline Gender & $7.48 * *$ & .033 \\
\hline LOC & $4.33^{*}$ & .020 \\
\hline Gender * LOC & .004 & .000 \\
\hline \multicolumn{3}{|l|}{ Distress-Reduction } \\
\hline Gender & 0.03 & .000 \\
\hline LOC & $4.22 *$ & .019 \\
\hline Gender * LOC & 0.12 & .001 \\
\hline \multicolumn{3}{|l|}{ Patient } \\
\hline Gender & $10.74 * *$ & .047 \\
\hline LOC & 1.78 & .008 \\
\hline Gender * LOC & 0.22 & .001 \\
\hline \multicolumn{3}{|l|}{ Careful } \\
\hline Gender & 2.25 & .010 \\
\hline LOC & 1.44 & .007 \\
\hline Gender * LOC & 0.43 & .002 \\
\hline$* \mathrm{p}<0.05, * * \mathrm{p}<0.00$ & & \\
\hline
\end{tabular}


Table 3.

LOC Score

Driving experience

amount

\begin{tabular}{|c|c|c|c|c|c|c|c|c|c|}
\hline MDSI factor & $\begin{array}{c}\text { Male } \\
(\mathrm{n}=99)\end{array}$ & $\begin{array}{c}\text { Female } \\
(n=122)\end{array}$ & $\begin{array}{c}\text { Total } \\
(\mathrm{n}=221)\end{array}$ & $\begin{array}{c}\text { Male } \\
(n=100)\end{array}$ & $\begin{array}{c}\text { Female } \\
(n=122)\end{array}$ & $\begin{array}{c}\text { Total } \\
(n=222)\end{array}$ & $\begin{array}{c}\text { Male } \\
(n=100)\end{array}$ & $\begin{array}{l}\text { Female } \\
(n=122)\end{array}$ & $\begin{array}{c}\text { Total } \\
(n=222)\end{array}$ \\
\hline Dissociative & .132 & $.253 * *$ & $.245 * *$ & -.133 & $-.295 * *$ & $-.248 * *$ & $-.213^{*}$ & .048 & $-.143^{*}$ \\
\hline Anxious & .128 & .032 & $.146^{*}$ & -.056 & $-.391 * *$ & $-.267 * *$ & $-.317 * *$ & $-.210^{*}$ & $-.324 * *$ \\
\hline Risky & .069 & .085 & .025 & .047 & .024 & .030 & -.049 & .003 & .072 \\
\hline Angry & .117 & .067 & .063 & .145 & .054 & .116 & -.153 & $.214^{*}$ & .115 \\
\hline High velocity & .048 & .136 & .083 & $.277 *$ & -.031 & $.132 *$ & -.157 & .127 & .042 \\
\hline Distress-reduction & .162 & .133 & $.141 *$ & .061 & .004 & .027 & -.054 & .092 & .017 \\
\hline Patient & -.083 & -.031 & -.025 & -.165 & -.077 & $-.140 *$ & .027 & -.027 & -.069 \\
\hline Careful & -.007 & -.160 & -.061 & -.161 & -.008 & -.085 & $.090 *$ & -.108 & -.045 \\
\hline LOC & & & & .071 & -.059 & .014 & -.073 & .028 & -.068 \\
\hline
\end{tabular}

Driving experience

duration

*p $<0.05 ; * * p<0.01$ (2-tailed) 